\title{
SOMEWHERE OVER THE RAINBOW: NARRATIVAS DE MÃES DE CRIANÇAS ARCO-ÍRIS
}

\author{
Mary Costa da Silva \\ Miriam Tachibana \\ Universidade Federal de Uberlândia, Uberlândia-MG, Brasil
}

\begin{abstract}
RESUMO
Visando a investigar a experiência emocional de mães que tiveram uma criança "arcoíris" após terem experienciado uma perda gestacional/neonatal, foram entrevistadas quatro mães de crianças arco-íris de até três anos de idade. As entrevistas foram mediadas por uma narrativa interativa e, após cada encontro, uma narrativa transferencial foi redigida pela entrevistadora. $O$ material foi analisado psicanaliticamente, segundo a Teoria dos Campos. Observou-se que as participantes, atravessadas por um enlutamento complexo, culpabilizaram-se pela perda e por terem seguido adiante no cuidado materno com os filhos arco-íris, oscilando entre a superproteção e o afastamento. Nota-se a importância de uma intervenção junto a esse coletivo, que geralmente só é foco de atenção (quando o é) durante a gestação/puerpério subsequente à perda gestacional/neonatal.
\end{abstract}

Palavras-chave: Maternidade; Relações mãe-criança; Família.

\section{SOMEWHERE OVER THE RAINBOW: NARRATIVES OF RAINBOW CHILDREN'S MOTHERS}

\begin{abstract}
Aiming to investigate the emotional experience of mothers who had a "rainbow" child after experiencing a gestational/neonatal loss, four mothers of rainbow children up to three years old were interviewed. The interviews were mediated by an interactive narrative. After each meeting, a transferential narrative was written by the interviewer. The material was analyzed psychoanalytically, according to the Theory of Fields. It was observed that the participants blamed themselves for the loss and for having carried on with the maternal care of the rainbow children, oscillating between overprotection and withdrawal. We have noticed the importance of intervention within this group, which is usually the focus of attention (when it is) only during the pregnancy/puerperium following the gestational/neonatal loss.
\end{abstract}

Keywords: Maternity; Mother-child relationships; Family. 


\title{
SOMEWHERE OVER THE RAINBOW: NARRATIVAS DE MADRES DE NIÑOS ARCOIRIS
}

\begin{abstract}
RESUMEN
Con el objetivo de investigar la experiencia emocional de madres que tuvieron un hijo "arcoiris" después de experimentar la pérdida gestacional/neonatal, se entrevistó a cuatro madres de niños arcoiris de hasta tres años de edad. Las entrevistas fueron mediadas por una narrativa interactiva. Después de cada encuentro, la entrevistadora redactó una narrativa transferencial. El material fue analizado psicoanalíticamente, según la Teoría de Campos. Se observó que las participantes se culpaban por la pérdida y por haber seguido adelante con los niños arcoíris, oscilando entre la sobreprotección y el retraimiento. Se señala la importancia de una intervención junto a este colectivo, a la que normalmente se dirige (cuando se lo hace) sólo durante el embarazo/puerperio tras la pérdida gestacional/neonatal.
\end{abstract}

Palabras clave: Maternidad; Relaciones madre-hijo; Familia.

Tem sido cada vez menos frequente a morte de um bebê durante a gestação ou o puerpério, diante dos maiores recursos tecnológicos que hoje são encontrados na realização do pré-natal e na internação junto a UTI neonatal (Oishi, 2014). Segundo Bailey et al. (2019), passadas as doze primeiras semanas gestacionais, há 95\% de chance da gravidez se desenvolver de forma bem-sucedida.

Embora a perda gestacional/neonatal seja pouco provável, sabemos que, quando esta ocorre, pode vir a se constituir como um fenômeno disruptivo na biografia da mulher (Lerner \& Faria, 2019). Isso porque, nesses casos específicos, soma-se ao luto frente à perda objetal um outro trabalho de luto que já envolveria questões narcísicas (Freire, 2012). Afinal, como o bebê desenvolve-se no corpo da mulher, ele ainda seria sentido, por ela, como um objeto legitimamente narcísico, às vias de objetalização (Aguiar \& Zornig, 2016).

Uma das estratégias defensivas para fazer frente a essa condição paradoxal de ser mãe e de não ser mãe (Freire, 2012) tem sido a de recorrer a uma nova gravidez, muitas vezes num curto espaço de tempo após a perda gestacional/neonatal, com a esperança de que o processo de luto seja finalizado com um novo bebê (Rodrigues, 2009; Vidal, 2010). Navidian et al. (2017), que realizaram um levantamento de diversos estudos sobre esse aspecto, notaram que, segundo diferentes pesquisas, mesmo que as mulheres fiquem absorvidas pelo medo de virem a sofrer nova perda gestacional/neonatal, $50 \%$ a 98\% dessas mulheres decidem engravidar novamente, dentro do prazo de um ano, após a vivência da perda.

Tem sido atribuído o termo "bebê arco-íris" a esse bebê que nasce depois de seus pais terem vivenciado uma perda gestacional/neonatal, uma vez que ele simbolizaria algo que vem após uma "tempestade". Não é de conhecimento público o autor deste termo, que tem se disseminado pelas redes sociais. A despeito de não sabermos muito sobre as origens do termo "bebê arco-íris", observamos que a comunidade científica, desde 1980, vem se debruçando sobre a relação entre a perda gestacional/neonatal e a condição emocional materna na gravidez subsequente (Vidal, 2010), partindo da compreensão de que essa perda anterior pode deixar cicatrizes na mulher, que influenciariam seu investimento psíquico nesse novo bebê. 
Dentre os trabalhos recentemente publicados, poderíamos destacar, por exemplo, o de Rodrigues (2009), realizado com 114 grávidas portuguesas que haviam perdido seus bebês em gestações anteriores. Foi possível notar que tais mulheres só conseguiram se investir psiquicamente nas gestações (subsequentes à perda), após terem ultrapassado a quantidade de semanas equivalentes à idade gestacional em que haviam sofrido a interrupção da gravidez anterior, adiando assim os preparativos para a chegada do bebê num movimento de autopreservação. Bailey et al. (2019), por sua vez, entrevistaram 14 gestantes inglesas que já haviam sofrido várias perdas gestacionais e que, por conta disso, apesar de esperarem pelo melhor, ficavam se preparando para o pior, verificando constantemente se havia sangue em suas calcinhas e tendo medo de se encontrar casualmente com pessoas a quem teriam que relatar a nova gravidez.

No Brasil, destacamos o valioso trabalho de Vidal (2010), que acompanhou quatro puérperas, que já haviam perdido bebês previamente, e que dirigiam a si mesmas um elevado grau de exigência, atravessadas pela fantasia onipotente de que a sobrevivência dos bebês arco-íris dependeria exclusivamente de seus cuidados. Há ainda o estudo brasileiro de Teodózio et al. (2020), em que foram entrevistadas quatro mulheres, que já haviam sofrido pelo menos uma perda, e a partir do qual foi possível notar que, em alguns casos, as mesmas roupas e os mesmos nomes dos bebês perdidos eram atribuídos ao bebê arco-íris, com o bebê perdido figurando como um "fantasma" no quarto do bebê arco-íris, "assombrando" o vínculo materno-filial.

Malgrado essas contribuições valiosas, notamos, em nosso levantamento bibliográfico, que os estudos têm se debruçado sobretudo sobre a experiência emocional da mulher enquanto ela se encontra gestante ou puérpera. Trata-se, assim, de investigações que versam sobre a experiência emocional materna em períodos muito precisos, quando o bebê arco-íris ainda não foi efetivamente conhecido ou quando ele está nas semanas iniciais de vida.

Para o psicanalista inglês Donald Winnicott, de fato, o bebê que se encontra nos primórdios da vida demanda bastante atenção por parte daqueles que lhe irão fornecer a provisão ambiental, tanto que ele ressaltava a importância de os profissionais da área de Obstetrícia constituírem um ambiente suficientemente bom para que as mães pudessem fazer o mesmo com seus bebês (Winnicott, 1957/1994). Entendemos, contudo, ainda apoiadas na obra winnicottiana, que o bebê e a mãe demandam se sentir emocionalmente sustentados não apenas no puerpério, fazendo-se necessário um olhar atento sobre essa díade também ao longo dos primeiros anos de vida da criança. Assim, a partir da escassez de contribuições científicas voltadas à experiência materna quando o filho arco-íris já não é mais um bebê recém-nascido, objetivamos investigar a experiência emocional de mulheres que sofreram uma perda gestacional/neonatal e que, atualmente, são mães de crianças arco-íris de até três anos de idade.

\section{MÉTODO}

Após a aprovação do projeto de pesquisa no Comitê de Ética de Pesquisa envolvendo seres humanos (CAAE: 20695719800005152), iniciamos a busca por possíveis participantes, solicitando indicações entre os nossos conhecidos. Ao final, contamos com a participação de quatro mulheres, cujas idades variaram entre 25 e 43 anos. 
Todas elas se encontravam em um vínculo conjugal estável com os pais de seus filhos (tanto dos filhos perdidos quanto dos filhos arco-íris), sendo que duas delas haviam sofrido perda neonatal, enquanto outras duas haviam perdido seus bebês ainda na gestação. Apenas uma das participantes havia sofrido cinco perdas e tinha três filhos vivos, enquanto as outras três participantes haviam sofrido uma única perda e tinham apenas um filho vivo. Visando a assegurar o anonimato, foram atribuídos nomes fictícios, inspirados nos fenômenos naturais que ocorrem no céu (como o arco-íris), a todas as participantes.

Foram realizadas entrevistas individuais conduzidas de acordo com o método psicanalítico, o qual prioriza as técnicas da associação livre e da atenção flutuante. Desta forma, não foi adotado um roteiro estruturado de perguntas, entendendo que, quanto mais livremente as participantes se expressassem, mais significativo seria aquilo que elas trariam.

No entanto, considerando que falar sobre perda gestacional/neonatal é muitas vezes algo emocionalmente difícil e que poderia despertar posturas defensivas nas participantes, adotamos um recurso mediador durante as entrevistas. Deste modo, este estudo teve como recurso a narrativa interativa, que consiste numa estratégia metodológica, inspirada no Jogo do Rabisco de Winnicott (1968/1994), e que tem sido usada em pesquisas winnicottianas. Trata-se de uma breve história fictícia, associada ao que se quer investigar, que é apresentada ao participante como rabisco inicial dos pesquisadores, e para a qual o participante é convidado a inventar um desfecho, apresentando o seu próprio rabisco (Granato et al., 2011). A narrativa interativa, especialmente elaborada para a realização dessa pesquisa, a partir da qual as entrevistas com as participantes se desdobraram, foi a seguinte:

"Ainda sonolenta, Sol abriu os olhos. Deitada em sua cama e olhando fixamente para o teto, ficou se lembrando de alguns fragmentos do sonho que acabara de ter. Não se lembrava direito dele, mas sabia que, em seu sonho, estava grávida. Enquanto Sol ainda ensaiava levantar-se, pegou seu celular e, em uma de suas redes sociais, viu que uma conhecida acabara de anunciar uma gravidez descoberta há poucos dias. Lembrou-se então de sua gestação que não dera certo e ficou pensando no quanto aquela sua conhecida poderia estar sendo, assim como ela, equivocadamente feliz. Mergulhada nesses pensamentos tristonhos, de repente, Sol escuta um barulho, vindo do lado de fora do quarto. Será que seu filho tinha acordado? Em meio a essas lembranças tristes e o momento presente, ela..."

Após cada encontro, a entrevistadora redigiu um texto relatando não apenas os atos e as falas das participantes, mas também, as suas impressões contratransferenciais, tão valiosas numa pesquisa psicanalítica. Deste modo, foi redigida uma narrativa transferencial (Aiello-Vaisberg et al., 2009) sobre cada entrevista, o que permitiu que cada um dos encontros fosse posteriormente revisitado, viabilizando as reflexões clínico-teóricas.

Assim, as quatro narrativas transferenciais (produzidas pela entrevistadora) e os desfechos das narrativas interativas (produzidos pelas participantes) foram reunidos e analisados psicanaliticamente, à luz da Teoria dos Campos, desenvolvida pelo psicanalista Fábio Herrmann. Esta teoria apresenta a noção de que o psiquismo humano é atravessado por vários campos relacionais, que definiriam a forma do indivíduo de 
representar a realidade e de consequentemente agir sobre ela (Sanches \& Cardoso Júnior, 2006). Neste sentido, usamos a Teoria dos Campos (Herrmann, 2007) para identificar quais eram os campos habitados pelas participantes, que possuíam em comum a experiência de perda gestacional/neonatal, seguida de uma nova gestação, entendendo que esses campos permitiriam o acesso à experiência emocional de maternar uma criança arco-íris.

\section{Resultados E Discussão}

A análise psicanalítica do material possibilitou a identificação de um campo intitulado "Ao final do arco-íris, persiste a tempestade", a partir do qual foi possível observar que, apesar das participantes terem tido filhos arco-íris, seguiam ainda bastante influenciadas pela "sombra" dos bebês que haviam perdido. Para ilustrar, apresentamos um trecho da narrativa transferencial com a participante Aurora, conforme segue:

Aurora conta que é mãe de um menino de três anos de idade, fruto de uma segunda gestação. Sua primeira gravidez, há 14 anos, causou-lhe um choque, já que ela tinha pouco tempo de relacionamento com o pai da criança (e que atualmente é seu marido e pai de seu segundo filho). Após duas semanas da descoberta, Aurora soube, entretanto, que se tratava de uma gravidez ectópica, que culminou num aborto espontâneo. Aurora conta que, como tudo ocorreu muito rapidamente, não chegou a revelar aos familiares sobre o ocorrido: "Até hoje a minha família não sabe dessa situação. Só as minhas irmãs mais próximas e algumas amigas sabem”. Chamou nossa atenção o fato que, embora Aurora dissesse não saber falar muito sobre sua experiência do aborto, narrou sobre isso com muita riqueza de detalhes, sendo capaz de citar o nome completo da médica que lhe atendera na primeira gestação, a despeito de não conseguir se recordar do nome do obstetra que lhe acompanhara na segunda gravidez. Ao final do encontro, Aurora falou: "É muito doído você saber que tem uma criança dentro de você e depois saber que já não tem mais. Porque você vai se acostumando com a ideia de ter alguém se desenvolvendo dentro de você, um serzinho. Ai depois não dá certo e vem um certo desesperinho, né?" Ao inventar o desfecho para a narrativa interativa, Aurora, colocando-se no lugar da personagem, diz que: "em meio a essas lembranças tristes e o momento presente, ela corre até o quarto e vê que está tudo bem com seu filho. Ele apenas estava sonhando e isso a deixa muito aliviada".

Apesar de Aurora ter feito movimentos na tentativa de minimizar a dor da perda sofrida, usando palavras no diminutivo (tais como "serzinho" e "desesperinho"), percebemos como a perda gestacional se mantinha bastante vívida para ela, seja por ela se lembrar de detalhes em relação à primeira gravidez, que ela já ignorava em relação à segunda, seja porque ela completara a narrativa interativa trazendo a preocupação de que algo de ruim pudesse ter ocorrido com o seu filho arco-íris. Nota-se, portanto, que arco-íris e tempestade se mesclavam, configurando o campo "Ao final do arco-íris, persiste a tempestade".

Seria possível, num primeiro momento, pensarmos que Aurora habitava o referido campo, uma vez que 14 anos ela carregava secretamente essa perda gestacional, 
o que equivaleria a uma espécie de "luto inibido", caracterizado pela incapacidade em lidar com a dor da perda (Barbosa \& Neto, 2010). Esse pacto do silêncio, numa tentativa de afastar o sofrimento, não seria incomum entre as mulheres que perderam os seus bebês (Aguiar \& Zornig, 2016; Lemos \& Cunha, 2015).

E aqui é possível pensarmos que essa estratégia de não tocar no assunto, como se os sentimentos já tivessem sido sepultados, corresponderia não apenas a um movimento individual de autopreservação, mas também a algo ancorado numa sociedade que tem uma relação com a morte marcada pela evitação e pela negação. O luto de Aurora, nessa perspectiva, não seria apenas um luto silencioso, optado por ela para seguir a vida como se nada tivesse ocorrido, mas também um luto silenciado, influenciado por uma sociedade que espera que tudo volte ao normal o mais rapidamente possível (Aguiar \& Zornig, 2016), ainda mais quando se trata da perda de um bebê que ainda não havia sido apresentado para o mundo (Coelho Filho \& Lima, 2017).

Nesse sentido, encontramos variados estudos (Lerner \& Faria, 2019; Melo \& Vaz, 2019; Muza et al., 2013) sobre a criação de websites e perfis na internet ou, ainda, sobre a participação (in)formal em grupos de autoajuda, por parte de mulheres que perderam os bebês, visando discutir publicamente sobre o assunto, justamente por se sentirem silenciadas em suas dores, pela sociedade, sendo atravessadas pelo sentimento de terem perdido a perda (Melo \& Vaz, 2019). A ideia é a de que a exposição da intimidade, a partir de narrativas biográficas publicamente compartilhadas, seria vivida como um ato terapêutico, com a mulher não apenas encontrando pares com os quais se identifica, via fenômeno de contágio e de espelhamento, mas também exigindo que a sociedade de maneira geral a repare pelo desmentido, isto é, pelo não reconhecimento de sua dor (Curi, 2016).

Em um segundo momento, podemos pensar que, talvez, o fato de Aurora habitar o campo "Ao final do arco-íris, persiste a tempestade" independesse dela não falado sobre a perda gestacional com várias pessoas. Isso porque, segundo Aguiar e Zornig (2016), é possível que esse movimento tenha efeitos psicopatológicos nos quais a discursivização que se daria seria a mera repetição traumática (Aguiar \& Zornig, 2016). Assim, segundo as autoras, essa estratégia pode tanto figurar como uma tentativa de elaboração do luto, com as mulheres encontrando um grupo de pertencimento que pode ter nuances de um espaço potencial (Winnicott, 1953/1975), isto é, de uma área intermediária entre a realidade interna e a realidade externa, que se configuraria como um local de refúgio, onde elas poderiam se colocar como mães de anjos e achar um meio entre as mães e não mães, como, num avesso, impedir justamente essa elaboração.

Desde essa perspectiva, não necessariamente falar sobre a perda do bebê seria, de saída, uma resposta mais criativa do que não falar sobre ela. Todavia, talvez perdure na comunidade psicológica a compreensão de que o enlutado que nada fala estaria pior do que aquele que fala bastante de sua dor pois, como destacam Lerner e Faria (2019), há, na sociedade, uma série de regras que são aplicadas aos enlutados. Logo, ao mesmo tempo em que a sociedade não dá conta de manifestações "extravagantes" de descontrole emocional, tampouco aceita que o enlutado não as expresse em absoluto, sob pena de ser visto como alguém que está negando os seus sentimentos.

Neste ponto, vale trazermos outro trecho de narrativa transferencial relativo à entrevista com Luna. Trata-se de uma participante que, no extremo oposto de Aurora, já assumia a postura de falar publicamente sobre suas cinco perdas gestacionais, consoante trecho que segue: 
Luna conta que teve sua primeira gestação aos 33 anos de idade, a qual resultou no nascimento de sua primeira filha, que atualmente tem oito anos de idade. A participante explica que foi uma gestação muito tranquila e que desejava ainda ter mais dois filhos. No entanto, devido às inúmeras complicações, acabou sofrendo cinco perdas gestacionais até que nascessem os seus outros dois filhos (que atualmente têm quatro e dois anos de idade). A participante explicou que se sentia muito culpada pelas gestações que não chegavam a termo, visto que já possuía uma idade considerada avançada para gestar e também alguns problemas de saúde. Logo, ela começou a falar sobre outra culpa que a permeava, em relação aos bebês arco-íris que ela tivera, pois, às vezes, parecia que ela estava tentando apagar a existência de seus outros filhos, sentimento este que acabava sendo amplificado pela sociedade com a ideia de que perdas gestacionais são passíveis de substituição. Ela diz: "Eu me faço essa pergunta várias vezes, mas o próprio nome 'arco-íris' já diz que ele vem depois de uma tempestade. Então ele não deixa você esquecer o que você passou. Ele só chega quando houve a tempestade e, sem ela, ele não existe”. A participante diz, porém, que sente que as pessoas a cobram para que ela se esqueça dos bebês que foram perdidos, uma vez que várias pessoas próximas já lhe haviam dito algo como: "Seus filhos são aqueles que estão aqui", o que lhe causava certa angústia, visto que ela se vê como mãe de oito crianças, mostrando considerar seus cinco filhos perdidos nessa contagem. Justamente por causa disso, Luna explicou que gostava de divulgar sua história nas redes sociais, porque sabia o quanto era importante as mães saberem que podem e devem falar sobre as perdas de seus filhos, citando inclusive seus nomes. Quando apresentada à narrativa interativa, Luna inventou um desfecho em que a protagonista Sol, ao ouvir um barulho vindo do quarto do filho, vai rapidamente conferir se estava tudo bem com ele. No entanto, a participante inclui na história a existência de um segundo filho, que teria sido perdido, e discorre que a protagonista.... 'Aproximou-se da cama e deu um beijinho delicado na bochecha de seu primogênito. Sim, primeiro de dois, pensou ela. Aquele menininho era o melhor irmão mais velho do mundo. Não seria, era. $O$ pensamento acalentou seu coração partido. Sentiu suas mãos aquecidas por um calor inexplicável, como se mãozinhas invisíveis as segurassem. Entre as lágrimas, sorriu, aquecida pelo imenso amor que tinha por seus dois filhos'.

A narrativa transferencial referente à entrevista com Luna revela não apenas que o campo "Ao final do arco-íris, persiste a tempestade" prescinde do fato de a mulher falar ou não sobre a morte de seu bebê, mas também que um dos elementos que fazem com que o arco-íris seja acometido pela tempestade é a culpa. E Luna fala sobre dois tipos distintos de culpa: 1) a culpa por ter perdido o bebê; e 2) a culpa por ter seguido adiante, engravidando novamente.

Em relação ao primeiro tipo de culpa, sabemos que, diante da morte, o indivíduo é inevitavelmente tomado pela necessidade de buscar uma explicação causal em que alguém acaba sendo duramente culpabilizado (Freire, 2012). Seria uma tentativa de tamponar a perda, buscando-se explicações (Lemos \& Cunha, 2015). Na maioria das vezes, nessa busca por um culpado, quem acaba sendo culpabilizado pela morte do bebê é a própria mãe, não apenas porque a gravidez se inscreve no corpo feminino (Lemos \& Cunha, 2015), mas também considerando o imaginário social que perdura ao redor da 
mãe. Afinal, persistimos numa sociedade em que a mulher é cobrada a procriar, a ter um parto normal, a se dedicar exclusivamente à amamentação de livre demanda..., com esse discurso autoritário sobre a maternidade inevitavelmente levando a mulher a se culpabilizar frente a qualquer inadequação (Halasi, 2018), principalmente em relação à "dívida" de não ter tido uma gravidez bem-sucedida.

Cabe refletirmos que, mesmo a Psicanálise, enquanto fruto da cultura, também não esteve isenta da reprodução dessas "regras" acerca do papel que é destinado à mulher/mãe na sociedade, havendo muitos trabalhos psicanalíticos que, apoiados numa concepção reducionista, potencializavam o sentimento de responsabilização da mãe pela perda gestacional/neonatal. A título de ilustração, na clássica obra psicanalítica "Maternidade e sexo", Langer (1986) apontava que, nos casos de perdas gestacionais repetidas, estaríamos diante de tentativas inconscientes da mulher de se desfazer do objeto, dada a sua incapacidade de sustentar o desejo do filho e o desejo de que a gravidez chegue a termo.

Em uma perspectiva psicanalítica diferente, compartilhamos o entendimento de que a questão não é que a perda do bebê estaria literalmente ligada a um desejo da mãe de eliminá-lo, que teria sido tão bem-sucedido a ponto de ser realizado, até porque compreendemos, à luz dos estudos de Winnicott (1950/1993), que todo indivíduo é atravessado por sentimentos de ódio, mesmo em relação aos objetos amorosos. Destarte, entendemos que é mais cauteloso abordarmos psicanaliticamente essa questão reconhecendo como natural que a mulher também tenha hostilidade em relação ao bebê, auxiliando-a para que não se martirize ao acreditar que a sua hostilidade teria efetivamente destruído o bebê. Trata-se de uma reflexão pautada na compreensão de que, de outro modo, a mulher acaba sofrendo duplamente: sofre pela perda do filho, mas também sofre por fantasiar (e por ser alvo também das fantasias dos demais) que a perda seria de sua responsabilidade (Melo \& Vaz, 2019).

Em relação ao segundo tipo de culpa apontado por Luna, ela foi igualmente notada em outros estudos psicanalíticos sobre o mesmo tema. Oishi (2014), que realizou um estudo de caso, por meio do qual uma mulher foi psicanaliticamente acompanhada após sofrer uma perda gestacional, observou que é comum a mulher sentir-se culpada, como se estivesse traindo o bebê falecido, deixando de lhe ser fiel ao se envolver maximamente com um novo bebê. Para Rodrigues (2009), em algumas situações radicais, a mulher pode inclusive chegar a ter dificuldade para desenvolver um vínculo com a nova criança, pois, ao mesmo tempo em que deseja ter um filho vivo e nele se investir, pode sentir-se culpada por não permanecer unida ao bebê falecido.

Haveria, assim, um dilema, vivido por algumas mulheres que sofreram perda gestacional/neonatal, pois, ao mesmo tempo em que há o desejo de ter um outro filho, há um mal-estar por não conservar o bebê morto como único objeto de amor. Assim, não obstante existir a compreensão de que a perda de um bebê pode vir a ser sentida como uma amputação para a mulher (Aguiar \& Zornig, 2016), é possível que, num grau mais extremo, seja experienciada uma sobreposição, de modo que uma "criança morta é também uma mãe morta" (Muza et al., 2013, p.37). Em outras palavras, a mãe pode acabar se identificando tanto com o bebê perdido que não consegue dele se separar.

Apresentamos, a seguir, um trecho da narrativa transferencial referente à entrevista com Celeste. Em seu caso, fica evidente que, atravessada pelo campo "Ao final do arco-íris, persiste a tempestade", o bebê perdido, a quem ela se mostrava maximamente identificada, se sobrepunha à filha arco-íris, conforme se verifica a partir da leitura que segue: 
Celeste conta que sua primeira filha nasceu com apenas cinco meses de gestação: "Ela nasceu perfeita, mas os órgãos não estavam totalmente formados". Infelizmente, a bebê foi a óbito três dias após o nascimento. Celeste narra que, mesmo com as contraindicações dos médicos, ela acabou engravidando novamente, dez meses após a perda neonatal. Ao chegar ao quinto mês de sua segunda gestação, Celeste novamente sentiu dores e teve sangramentos, mas, desta vez, foi submetida ao procedimento de cerclagem, de modo que sua segunda filha nasceu apenas ao final dos nove meses de gestação. Celeste narra como se sentiu em sua segunda gestação: "Mesmo dando os pontos, eu ainda tinha medo. Até quando ela nasceu, eu ainda tinha medo. Eu só fui ficar tranquila depois que eu a peguei no colo". Logo em seguida, a participante para de falar sobre a bebê arco-íris e volta a discorrer sobre o primeiro bebê que tivera: "Era uma menina perfeita, não tinha nada de deficiência". Em dado momento da entrevista, sua segunda filha, atualmente com dois anos de idade, entrou no cômodo da casa em que a conversa estava ocorrendo e começou a brincar. Nesse momento, é possível notar que a criança apresenta em seu rosto algumas características de deficiência física, mas Celeste não toca no assunto em nenhum momento. De repente, a criança começou a chorar, após bater a cabeça na porta sem querer. Sem ir até a sua filha para verificar o machucado, Celeste pede para que ela vá procurar pelo pai. Logo mais, ao final da entrevista, quando apresentada à narrativa interativa, Celeste diz, de maneira bem objetiva, que, se a situação fosse com ela, após ouvir o barulho, iria até o quarto conferir se estava tudo bem com a filha.

A partir desse material, notamos que Celeste se mostrava ainda bastante investida em sua primeira bebê, descrita por várias vezes como "perfeita" e de quem ela, por associação livre, acabou falando mais do que da nova filha, ao longo da entrevista. Paralelamente, observamos que o olhar de Celeste se voltava menos para a criança arcoíris, pois, apesar de ter inventado um desfecho para a narrativa interativa, dizendo que a personagem iria até o quarto para verificar se estava tudo bem com a filha, ao longo da entrevista, ela acaba justamente apresentando o movimento contrário.

Ao ver que a filha se machucara, ao correr pela casa, a participante, ao invés de ir justamente verificar o que havia ocorrido, tal como no desfecho inventado da narrativa interativa, apenas incentiva que a criança procure pelo pai. Para além disso, podemos entender que o fato de Celeste não falar em absoluto da deficiência visível de sua segunda filha poderia também ser um indicador do quanto essa mãe se sentia mais próxima do bebê perfeito falecido do que da filha arco-íris "imperfeita".

De acordo com Vidal (2010), mesmo nos casos em que o bebê arco-íris não apresenta qualquer tipo de deficiência, haveria uma tendência, por parte das mães, em manterem o bebê morto no terreno da idealização, comparativamente à criança viva e concreta que advém de uma gravidez subsequente. No caso específico de Celeste, cuja filha arco-íris apresentava uma deficiência, podemos pensar que a distância entre a bebê perdida ideal e a filha arco-íris real restasse ainda maior, promovendo também um distanciamento afetivo na relação entre Celeste e sua segunda filha.

É possível também pensarmos que, talvez, a deficiência da filha arco-íris despertasse na participante a fantasia de que ela não seria capaz de gerar uma criança saudável e perfeita. Desde essa perspectiva, a não nomeação de Celeste em relação à 
deficiência da filha seria não apenas uma recusa em olhar para essa criança imperfeita, tão diferente da primeira filha idealizada, mas também um distanciamento frente à fantasia de sua incapacidade reprodutiva, vale dizer, da fantasia de que ela própria fosse uma mãe "deficiente" (Lemos \& Cunha, 2015). Independentemente dos fatores que estariam interatuando nessa dinâmica relacional, notamos que a filha arco-íris parecia ser vivida como uma estranha, aos olhos da mãe, que se mantinha mais familiarizada com a bebê perdida anteriormente.

Seria possível refletirmos aqui que, talvez, se Celeste de fato tivesse seguido as recomendações médicas de não engravidar tão cedo, novamente, teria tido melhores chances de se vincular ao bebê arco-íris. Sousa e Lins (2020), que entrevistaram cinco grávidas que haviam sofrido perda gestacional prévia, constataram que, dado o curto período entre a perda anterior e a descoberta da nova gravidez, as participantes tinham a impressão de que não haviam vivenciado suficientemente o luto. Verifica-se assim que, apesar de muitas mulheres optarem por engravidar novamente bem rapidamente, não se vendo capazes de desinvestir da gravidez onde havia um hiperinvestimento (Freire, 2012), comumente a nova gravidez não exerce de fato um efeito positivo em seus processos de elaboração de luto.

Oishi (2014) ressalta, contudo, que nem sempre esse movimento das mulheres no sentido de engravidarem rapidamente, após uma perda gestacional/neonatal, decorreria de um desejo intrapsíquico quase obsessivo de ter outro filho. Segundo a autora, grande parte dessas mães enlutadas sofreria também uma pressão das famílias e da sociedade, de maneira geral, para fazer rapidamente esse deslocamento, tanto que, em seu estudo, a participante queixava-se dos comentários que lhe faziam, para consolála, tais como: "logo você terá outro". Neste sentido, haveria também uma pressão ambiental convocando a mulher a fazer a reposição desse filho o mais rapidamente possível.

Portanto, o campo "Ao final do arco-íris, persiste a tempestade", que atravessava as participantes desse estudo, nos convida a pensar sobre o entorno vivido por elas, numa perspectiva intersubjetiva. Afinal, trata-se de um campo que não diz respeito apenas à relação da mulher com o bebê perdido e com o filho arco-íris, mas também com as relações outras que ela experiencia. Essa questão fica evidente no seguinte trecho de narrativa transferencial relativa à entrevista com outra participante:

Iris conta que, quando completou 27 semanas de idade gestacional, sofreu um acidente de moto e foi necessário fazer um parto cesárea de urgência. Infelizmente, devido à prematuridade e a infecções adquiridas no hospital, seu bebê sobreviveu por apenas 16 horas. Ela conta que, logo que saiu do hospital, após sua perda neonatal, sabia que queria ter um outro filho, tanto que se viu novamente grávida, seis meses após a perda. Ela diz que se sentiu muito confusa durante essa segunda gestação: "Até mesmo porque foi uma atrás da outra e muita gente não sabia o que tinha acontecido. Eu sabia que queria outro filho, mas não sabia que seria tão difícil lidar com aquilo que eu ainda não tinha superado. Acho que eu tinha que ter dado um tempo, ter vivido aquele momento". Iris fala também que se frustrava, pois queria que o marido sofresse o mesmo tanto que ela: "A gente não conversa sobre. Eu não sei se ele simplesmente seguiu a vida ou se ele só não gosta de falar". Iris explicou que, durante essa segunda gravidez, sentia muito medo de tudo, de andar na rua, de subir escadas, de sentar em cadeiras com receio de que algo pudesse acontecer. 
A participante diz que até hoje, que seu filho tem dois anos de idade, ela tem receio, por exemplo, de que ele seja alimentado por outras pessoas (de modo que, quando ela sai com ele, carrega consigo várias comidas prontas). Iris conta que foi também deixando de conviver com algumas pessoas com medo de que façam algo com seu filho que esteja fora de seu controle ou, ainda, que a critiquem sobre a forma como ela vive sua maternidade. Diz que faz isso porque não teve a oportunidade de acompanhar o seu primogênito como gostaria: "Eu não vi ele crescer, eu não vi ele andar, eu não levei ele nas vacinas, ele não conversou, ele não sorriu. Então com esse eu queria estar lá. Se ele piscasse, eu queria ver". Ao final da entrevista, ao ser apresentada à narrativa interativa, a participante disse que teria um compromisso naquele horário e pediu para enviar o seu desfecho posteriormente. Contudo, Iris não deu mais nenhum retorno, mesmo após nova tentativa de contato com ela uma semana depois.

A partir desse excerto, vemos como Íris se mostrava bastante confusa em relação à maternagem de seu segundo filho, relacionando-se com ele ainda bastante permeada por sentimentos em relação ao bebê que perdera. Trata-se de algo que Vidal (2010) também observou, descrevendo que, em alguns casos, dar-se-ia um verdadeiro processo de distorção na percepção materna, na qual a mulher apresenta comportamentos de superproteção e de hipervigilância em relação à saúde e à segurança do bebê arco-íris, com o receio de vir a sofrer nova perda.

Embora, num primeiro momento, possa parecer que a postura superprotetora de Íris correspondesse a algo completamente diverso da postura mais distanciada de Celeste, podemos pensar que ambas as situações equivaleriam aos dois lados de uma mesma moeda. Com efeito, em ambos os casos, as mulheres estariam atravessadas pelo campo "Ao final do arco-íris, persiste a tempestade", relacionando-se com os filhos arco-íris em função dos bebês perdidos: ora os vendo como os filhos imperfeitos, se comparados aos bebês perdidos, ora os vendo como os filhos com quem tudo deve se dar perfeitamente, já que não foi possível com os bebês falecidos. Trata-se de uma situação preocupante, uma vez que, nas duas situações, o cuidado materno poderia vir a comprometer o desenvolvimento emocional da criança. Segundo Kancyper (2019), que realizou um estudo de caso psicanalítico com uma mulher adulta, que havia sido uma bebê arco-íris, é possível que a criança acabe se constituindo psiquicamente imbuída "da função de mero objeto parcial, à semelhança de um pseudópode suplementar de um ser que - como uma ameba incompleta - precisa ser narcisizado por outro, porque adoece de uma inacabada estruturação psíquica" (Kancynper, 2019, p. 264).

Winnicott (1956/1993) denominou de "preocupação materna primária" o estado preocupado da mulher, que já se faria presente no final da gestação e que perduraria durante as primeiras semanas de vida do bebê, e que seria fundamental para que a mãe conseguisse se identificar sensivelmente com as necessidades o bebê, tendo condições de se adaptar às suas necessidades, para que, a partir daí, a criança pudesse continuar se desenvolvendo psiquicamente. Porém, para ele, era importante que a mãe conseguisse retomar, gradativamente, suas atividades e interesses pessoais, recuperando-se da preocupação materna primária; caso contrário, haveria o risco dela e do bebê não experienciarem um processo de individuação, tão necessário para que o bebê possa amadurecer emocionalmente.

As pesquisadoras winnicottianas Granato e Aiello-Vaisberg (2002), fazendo uma reflexão sobre o conceito winnicottiano de preocupação materna primária, propõem que, 
em algumas situações, seria difícil para a mulher poder sair dessa condição emocional. Ao observarem um grupo de mães de crianças com deficiência severa, as autoras identificaram que, nessa situação específica, as mulheres eram convocadas a exercer maior cuidado com os filhos, por um período ilimitado, vivenciando aquilo o que elas entenderam ser um estado de "preocupação materna primária especial" (p. 87). Seria especial, visto que, ao invés da mulher poder amenizar os cuidados à medida que a criança vai caminhando rumo à independência, ela precisaria continuar nesse estado de devoção, devido à condição de maior dependência ao ambiente que algumas crianças com deficiência podem apresentar.

Seria possível pensarmos que, como Iris se mostrava incapaz de afrouxar nos cuidados em relação ao filho arco-íris, parecia estar atravessada por uma preocupação materna primária especial. Assim, apesar de seu filho ter a capacidade de se desenvolver rumo à independência, a participante via-se incapaz de diminuir os cuidados a ele destinados, como se ele fosse, de fato, uma criança com limitações, talvez por ainda vêlo à sombra do primeiro filho, cuja vida havia sido efetivamente limitada.

Tal como Winnicott (1957/1994) entendia que, para que a mãe pudesse constituir um ambiente suficientemente bom para o bebê, fazia-se necessário que ela própria pudesse sentir-se emocionalmente sustentada pelo ambiente, podemos pensar que, ao longo da entrevista, Íris comunica não apenas que a sua relação com o filho arco-íris estivesse adoecida, como também que o ambiente se revelava empobrecido para ela. Isso fica claro quando ela discorre sobre a impossibilidade de conversar sobre o bebê perdido com o seu marido, assim como fica evidente quando ela relata se sentir mais julgada do que cuidada pelos outros, no que diz respeito aos cuidados dedicados ao filho arco-íris. É possível inclusive pensarmos que, talvez, a participante tenha atuado transferencialmente, junto à pesquisadora, em relação à sua necessidade de se afastar dos outros, para não se sentir julgada por ela, no que se refere a esse movimento de superproteção, quando opta por não realizar a criação do desfecho da narrativa sugerida naquele momento (e depois desaparece, sem cumprir o combinado). Teria a participante ficado receosa quanto à proximidade da pesquisadora em relação a sua intimidade com o filho?

Vemos assim que a mulher que sofreu uma perda gestacional/neonatal demanda um ambiente cuidadoso para com ela, mas que esse cuidado exige extrema sensibilidade da parte do cuidador, não apenas porque cada mulher apresenta necessidades muito distintas (enquanto umas preferem não falar sobre o assunto, outras já se sentem silenciadas se não puderem conversar sobre), mas também porque certas intervenções, que a priori seriam zelosas, podem ser sentidas como mais disruptivas do que cuidadosas, fazendo com que a mulher sinta a necessidade de se afastar de todos. Tratase de um grande desafio, principalmente quando nos damos conta de que as ações de cuidado, por parte dos profissionais da área de saúde, tendem a ser mais pautadas em protocolos tecnicistas (Barbosa et al., 2012). 


\section{CONSIDERAÇÕES FINAIS}

A partir desse estudo, foi possível observar que as participantes habitavam o campo "Ao final do arco-íris, persiste a tempestade", no qual elas apresentavam manifestações particulares frente à dor do luto, embora todas se culpabilizassem, seja por se sentirem responsáveis pela perda, seja por terem seguido adiante com novas gestações. Ainda, em relação ao cuidado materno com os filhos arco-íris, notou-se que as participantes oscilavam entre uma postura de superproteção e de afastamento, estando ainda permeadas por sentimentos quanto ao bebê perdido.

Conquanto consideremos esse estudo valioso, já que não limitamos o nosso olhar à maternagem experienciada quando o fruto da gravidez subsequente à perda gestacional/neonatal é ainda um bebê de poucas semanas de vida, sustentamos que seriam importantes estudos inovadores que dessem voz a outros integrantes do ambiente familiar, tal como os pais e os irmãos, por exemplo. Isso também auxiliaria no sentido de descentralizar o debate sobre as questões associadas à perda gestacional/neonatal, tão focado ainda na figura da mulher.

No que concerne à mulher, pudemos perceber que, mesmo após ter tido uma gravidez bem-sucedida depois de viver uma perda gestacional/neonatal, ela ainda demanda atenção por parte dos profissionais da área de saúde. Esse cuidado, quando disponibilizado, pode auxiliar não apenas a mulher (em relação à elaboração da perda anterior e, também, em sua relação com o filho arco-íris), mas também a própria criança, que se beneficiaria indiretamente das intervenções dedicadas à sua mãe. Notamos, em contrapartida, que tais intervenções precisam estar pautadas na compreensão de que o processo de elaboração da perda é muito singular, sendo importante que o cuidado ofertado dê conta de reconhecer as mães em suas diferentes nuances, tais como as múltiplas cores que compõem, ao final, o arco-íris.

\section{REFERÊNCIAS}

Aguiar, H., \& Zornig, S. (2016). Luto fetal: A interrupção de uma promessa. Estilos da Clínica, 21(2), 264-281. http//dx.doi.org/0.11606/issn.1981-1624.v21i2p264-281

Aiello-Vaisberg, T. M. J., Machado, M. C. L., Ayouch, T., Caron, R., \& Beaune, D. (2009). Les récits transferenciels comme présentation du vécu clinique: Une proposition méthodologique. In D. Beaune (Org.), Psychanalyse, Philosophie et Art: Dialogues (pp. 39-52). L'Harmattan.

Bailey, S. L., Boivin, J., Cheong, Y., Kitson-Reynolds, E., Bailey, C., \& Macklon, N. (2019). Hope for the best... but expect the worst: A qualitative study to explore how women with recurrent miscarriage experience the early waiting period of a new pregnancy. BMJ, 9(5), 1-9. http://dx.doi.org/10.1136/bmjopen-2019-029354

Barbosa, A., \& Neto, I. (2010). Processo de luto. In A. Barbosa (Org.), Manual de cuidados paliativos (pp. 487-532). Faculdade de Medicina de Lisboa.

Barbosa, A. S. S. de F., Bobato, J. A. C., \& Mariutti, M. G. (2012). Representações de profissionais da saúde pública sobre o aborto e as formas de cuidado e acolhimento.

Revista da SPAGESP, 13(2), 44-55. Disponível em: http://pepsic.bvsalud.org/scielo.php?script=sci_arttext\&pid=S1677-

29702012000100006\&lng=pt\&nrm=i\&tlng=pt 
Coelho Filho, J. F., \& Lima, D. M. de A. (2017). Luto parental e construção identitária: Compreendendo o processo após a perda do filho. Psicologia Argumento, 35(88), 16-32. http://dx.doi.org/10.7213/psicolargum.35.88.AO02

Curi, P. L. (2016). Da curetagem aos restos psíquicos. Cadernos de Psicanálise SPCRJ, 32(1), 52-59.

Freire, T. C. G. P. (2012). Transparência psíquica em nova gestação após natimorto [Dissertação de Mestrado], Universidade de Brasília. Repositório institucional da UnB. https://repositorio.unb.br/handle/10482/11514

Granato, T. M. M., \& Aiello-Vaisberg, T. M. J. (2002). A preocupação materna primária especial. Psicologia Clínica, 14, 87-91.

Granato, T. M. M., Corbett, E., \& Aiello-Vaisberg, T. M. J. (2011). Narrativa interativa e psicanálise. Psicologia em Estudo, 16(1), 157-163. https://doi.org/10.1590/S141373722011000100018

Halasi, F. de S. (2018). A mulher brasileira contemporânea e a maternidade da culpa [Dissertação de Mestrado], Pontifícia Universidade Católica de São Paulo. Biblioteca digital de Teses e Dissertações da PUC São Paulo. https://tede2.pucsp.br/handle/handle/21668

Herrmann, F. (2007). Teoria dos Campos: Uma pequena história. Jornal de Psicanálise, 40(73), 69-75. Disponível em: http://pepsic.bvsalud.org/scielo.php?script=sci_arttext\&pid=S010358352007000200004

Kancyper, L. (2019). O irmão de substituição: O complexo fraterno no processo analítico de adultos. In L. Kancyper (Org.), O complexo fraterno (pp. 249-287). Blucher.

Langer, M. (1986). Maternidade e sexo: Estudo psicanalítico e psicossomático. Artes Médicas.

Lemos, L. F. S., \& Cunha, A. C. B. (2015). Concepções sobre morte e luto: Experiência feminina sobre a perda gestacional. Psicologia, Ciência e Profissão, 35(4), 11201138. https://doi.org/10.1590/1982-3703001582014

Lerner, K., \& Faria, A. F. (2019). "Reaprender a viver": Os sentidos da morte e do sofrimento entre mães que perderam filhos. Revista M: Estudos sobre a morte, os mortos e o morrer, 4(7). http://dx.doi.org/10.9789/2525-3050.2019.v4i7.180-200

Melo, C. T. V., \& Vaz, P. R. G. (2019). Perda gestacional e neonatal, um sofrimento $\begin{array}{llll}\text { como outro } \quad \text { qualquer. } & \text { Matrizes, }\end{array}$ http://dx.doi.org/10.11606/issn.1982-8160.v13i2p91-112

Muza, J. C., Sousa, E. N., Arrais, A. R., \& Iaconelli, V. (2013). Quando a morte visita a maternidade: Atenção psicológica durante a perda perinatal. Psicologia, Teoria e Prática, 15(3), 34-48. Disponível em: http://pepsic.bvsalud.org/scielo.php?script=sci_arttext\&pid=S151636872013000300003

Navidian, A., Saravani, Z., \& Shakiba, M. (2017). Impact of psychological grief counseling on the severity of post-traumatic stress symptoms in mothers after stillbirths. Issues in Mental Health Nursing. https://doi.org/10.1080/01612840.2017.1315623

Oishi, K. L. (2014). O Jardim de Julia: A vivência de uma mãe durante o luto. Psicologia, Teoria e Pesquisa, 30(1), 5-11. https://doi.org/10.1590/S010237722014000100002 
Rodrigues, A. S. N. (2009). Impacto de uma interrupção espontânea da gravidez na vinculação pré-natal numa gravidez seguinte [Dissertação de Mestrado], Universidade de Lisboa. Repositório Institucional da Universidade de Lisboa. https://core.ac.uk/download/pdf/12422423.pdf

Sanches, A., \& Cardoso Junior, H. R. (2006). Ruptura de Campo: Proposta clínica e metodológica de Fábio Herrmann. Anais do XIX Encontro de Psicologia e VI Encontro de Pós-Graduação: Percursos e Perspectivas. UNESP.

Sousa, T. B. E., \& Lins, A. C. A. A. (2020). Repercussões psicológicas da gestação em curso em mulheres com histórico de perda. Pesquisas e Práticas Psicossociais, 15(2), 1-15. Disponível em: http://pepsic.bvsalud.org/scielo.php?script=sci_arttext\&pid=S180989082020000200005

Teodózio, A. M., Barth, M. C., Wendland, J., \& Levandowsli, D. (2020). Particularidades do luto materno decorrente de perda gestacional: Estudo qualitativo. Revista $\quad$ Subjetividades, $\quad 20(2), \quad 1-14$. https://doi.org/10.5020/23590777.rs.v20i2.e9834

Vidal, M. (2010). Gravidez após morte perinatal: Sobre a relação da mãe com o bebê sobrevivente. Ciência \& Saúde Coletiva, 15(2), 31853190. https://doi.org/10.1590/S1413-81232010000800023

Winnicott, D. W. (1975). Objetos transicionais e fenômenos transicionais. In D. W. Winnicott (Org.), O brincar e a realidade (pp. 10-47). Imago. (Trabalho original publicado em 1953)

Winnicott, D. W. (1994). A contribuição da psicanálise à obstetrícia. In D. W. Winnicott (Org.), Os bebês e suas mães (pp.61-72). Martins Fontes. (Original publicado em 1957).

Winnicott, D. W. (1993). A preocupação materna primária. In D. W. Winnicott (Org.), Da pediatria à psicanálise: Obras escolhidas (pp.491-498). Imago. (Original publicado em 1956)

Winnicott, D. W. (1993). Agressão e sua relação com o desenvolvimento emocional. In D. W. Winnicott (Org.), Textos selecionados: Da Pediatria à Psicanálise (pp.355374). Francisco Alves. (Original publicado em 1950).

Winnicott, D. W. (1994). O Jogo do Rabisco. In C. Winnicott, R. Sheperd, R., \& M. Davis (Orgs.), Explorações psicanalíticas D.W. Winnicott (pp. 230-243). Artes Médicas (Original publicado em 1968).

Submetido: 04/03/2021

Reformulado: 08/05/2021

Aceito: 12/05/2021

\section{Sobre as autoras:}

Mary Costa da Silva é psicóloga pela Universidade Federal de Uberlândia.

Miriam Tachibana é docente do Instituto de Psicologia da Universidade Federal de Uberlândia.

E-mail de correspondência: mirita@ufu.br 